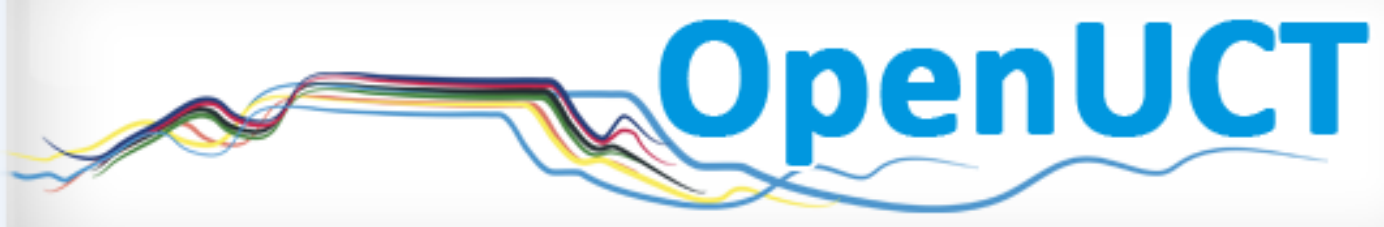

This is the author-approved manuscript version of a journal article published in:

Ng'ambi, D. \& Goodman, S. 2009. Bridging distance between actual and potential development: a case of using ICT mediated consultation tool. Education and Information Technologies. 14(1): 89-102. DOI: 10.1007/s10639-008-9074-8.

It is made available under the terms of agreement between the author and the journal, and in accordance with the University of Cape Town's Open Access Policy for the purposes of research, teaching and private study.

http://www.openuct.uct.ac.za/sites/default/files/UCTOpenAccessPolicy.pdf 


\title{
Bridging distance between actual and potential development: A case of using ICT mediated consultation tool
}

\author{
D. Ng'ambi \\ Centre for Educational Technology, University of Cape Town, Cape Town, South Africa \\ E-mail: Dick.Ngambi@uct.ac.za \\ S. Goodman \\ Centre for Management Studies, University of Cape Town, Cape Town, South Africa
}

\begin{abstract}
It is an ongoing challenge in higher education context to design appropriate learning tasks for students that balances the diversity in student knowledge and variable skills with student's potential to learn under guidance. Obtaining feedback from students on what they know is made more complicated when students are passive during learning activities. In this paper we report on a project that ran over 2 years in which 67 students (28 in 2005; 39 in 2006) from culturally diverse socio-historical backgrounds used an anonymous knowledge sharing tool, the dynamic frequently asked questions (DFAQ) to engage with authentic learning tasks in an Organisational Learning Module. The module was part of the Organisational Psychology honours degree programme at a higher learning institution. The students used the DFAQ tool to consult with both peers and faculty staff. DFAQ is a special purpose web-based tool with a Short Message Services (SMS) interface. A thematic analysis was conducted on students' experiences gathered from focus group discussions. Artefacts from DFAQ are also analysed. The paper reports that DFAQ mediated the educator's access to the students' level of understanding and the potential to learn under guidance. The DFAQ tool therefore allowed the educator to provide students with appropriate guidance that met individual students' knowledge gaps. The paper concludes that DFAQ mediated access to the gap between actual and potential development, stimulated knowledge sharing, peer learning and impacted on pedagogical designs of learning tasks.
\end{abstract}

Keywords: Knowledge sharing tool; Mediating learning gaps; Anonymous consultation; DFAQ 


\section{Introduction}

Among other challenges facing higher education institutions in South Africa is the need to align pedagogical designs to individual students' knowledge levels. This problem is compounded by increased diversity of socio-historical backgrounds of students, variable preparedness and large class sizes. Thus, the educators' challenges lie in understanding what students know so as to provide them with personalized guidance in contexts where students are generally passive learners. Our thesis is that student questions may provide a window into multiple perspectives of understanding particular concepts thereby giving useful feedback to the educator on both what students know and what they still need to know. We argue that multiple perspectives of students provide useful teaching and learning opportunities. The teaching opportunity lies in using the gap between what students know and what they potentially could know, to shape the design of learning tasks so that these tasks are sensitive to the cohorts' knowledge levels. The researchers were influenced by the Vygotskian notion of Zone of Proximal Development (ZPD). According to Vygotsky ZPD is the distance between levels of actual development as determined by independent problem solving and the level of potential development as determined through problem solving under adult guidance or in collaboration with more capable peers (Vygotsky 1978: 90). We were motivated by the learning opportunity which lay in allowing students to receive individualised support through collaboration with peers. The outcome of such collaboration was a knowledge resource of multiple views (responses) from peers on questions resulting in a dynamic repository of student's knowledge progression over time. In the context of this project, a student question served as an invitation to peers to help in searching for answers and multiple perspectives received were indicators of level of knowledge. Ng'ambi (2004) argues that a deluge of artifacts from student contributions in DFAQ are indicative of what students know and need to know. To this end, DFAQ mediated access to student knowledge levels, responses pointed students to what they could possibly know, and multiple perspectives were indicative of the class's knowledge level on whose basis the educator adjusted teaching activities in face-to-face sessions.

\section{Theoretical underpinning}

This paper draws on Jansen's (2004: 165) view of the sociology of knowledge which views knowledge, and how it is constituted, as a cultural product shaped by social context and history. According to Jansen, knowledge cannot be treated as a thing in itself, as a universally valid body of facts and theories, but must be understood in relation to the social setting in which it originated. This notion is particularly pertinent in educational context with diverse student body. In this study, the social origins of knowledge (context of a learner) were sandwiched between the curriculum students' needed to understand and the multiple perspectives shaped by sociohistorical backgrounds of individual students. Thus, students used the curriculum to trigger enquiry and drew on the sociology of the class to help themselves learn. Students' multiple perspectives were a product of diversity which in turn produced 
multiple views. Salmon (2000) argues that knowledge is acquired and assimilated in the context of the learner and in this way has a transformative effect on the learner. We infer from Salmon that knowledge acquisition among students is an interdependent process of reaching individual understanding of curriculum knowledge and while contributing to helping others reach their own understanding. This means that individual students are responsible for their own learning. Marquardt (2005) postulates questions are invitations of others to the process of searching for answers whereby sharing responsibility of what is known or understood.

Thus, our view of collaborative learning through peer consultation is that students expose their current levels of knowledge through asking questions and thereby take responsibility for their own learning. The deluge of elicited responses further exposes the collective knowledge levels of a class. It follows that collaborative learning through peer consultation reveals the gap between levels of actual development and the potential development under educator's guidance. In investigating these arguments, we allowed students to post questions anonymously to which other students attempted to respond.

This paper presents a research project that sought to explore how students acquired knowledge from consultation with peers about learning tasks and in particular how the social and historical context of students' shaped the multiple perspectives from which individualised guidance for students were given. Ng'ambi (2004) reports that,

when given a task, students tended to cluster themselves in either pairs or small groups of friends to source from each other and exchange 'knowledge'. Consultations were limited within clusters of friends and not based on asking knowledgeable peers. Students often preferred consulting peers rather than consulting subject experts or tutors (p. 85).

$\mathrm{Ng}$ 'ambi thus suggests that student knowledge is shaped by the topic of consultation and the community with whom one is consulting. To this end, this project was premised on the work of researchers like Belanger and Jordan (2000) and Ng'ambi (2004) who report that when learners each bring their analytical perspectives into the classroom and share their multiple perspectives in a group interactive session, the group environment can help facilitate the creation of new patterns of understanding built on the foundation of shared individual perspectives. These multiple perspectives also facilitate the process of evaluation of concepts, as learners begin to assign relative value to the individual perspectives (Belanger and Jordan 2000). It can therefore be inferred that students' multiple perspectives on a topic may be brought to bear during peer consultations and that embodied in questions are individual perspectives which are a product of community perspectives. Accepting this argument, it stands to reason that artefacts of student consultation could provide invaluable insights into students' knowledge levels and the potential of learning with scaffolding.

Ng'ambi (2004) identified three problems associated with students' face-to-face knowledge seeking and acquisition processes: Firstly, student consultations were limited to clusters of friends and not necessarily to knowledgeable peers. Secondly, there were no way a subject expert would know what knowledge exchanged among students and thirdly, consultations do not involve experts but students 
helping one another. To address these problems, Ng'ambi (2004) designed and developed an anonymous consultation tool, DFAQ. Figure 1 depicts part of the DFAQ interface.

In the next section, we discuss the research method. In particular we describe the context in which the study was conducted and how data was collected. Also discussed are the data analysis methods employed. This is followed by a discussion on the findings.

\section{Method}

The case study method was used to explore how the use of the DFAQ facilitated student learning, joint problem solving, knowledge sharing and collaboration in a specific setting. This method involves qualitative research techniques designed to describe how individuals ascribe meaning to their acts and problems and what those meanings are. The researchers wanted to explore students' perceptions of the DFAQ and investigate whether it was used for its intended purpose. The intended purpose of DFAQ was to empower students to ask questions they would otherwise not ask in face to face sessions for reasons not limited to shyness, fear of ridicule, lack of confidence, domination by others, socio-cultural reasons etc. As a case study we sought to understand the phenomenon of DFAQ mediated access to student knowledge levels in a bounded context. One of the greatest challenges of working within a case study methodological strategy is defining the case (Miles and Huberman 1994). We now describe the case.

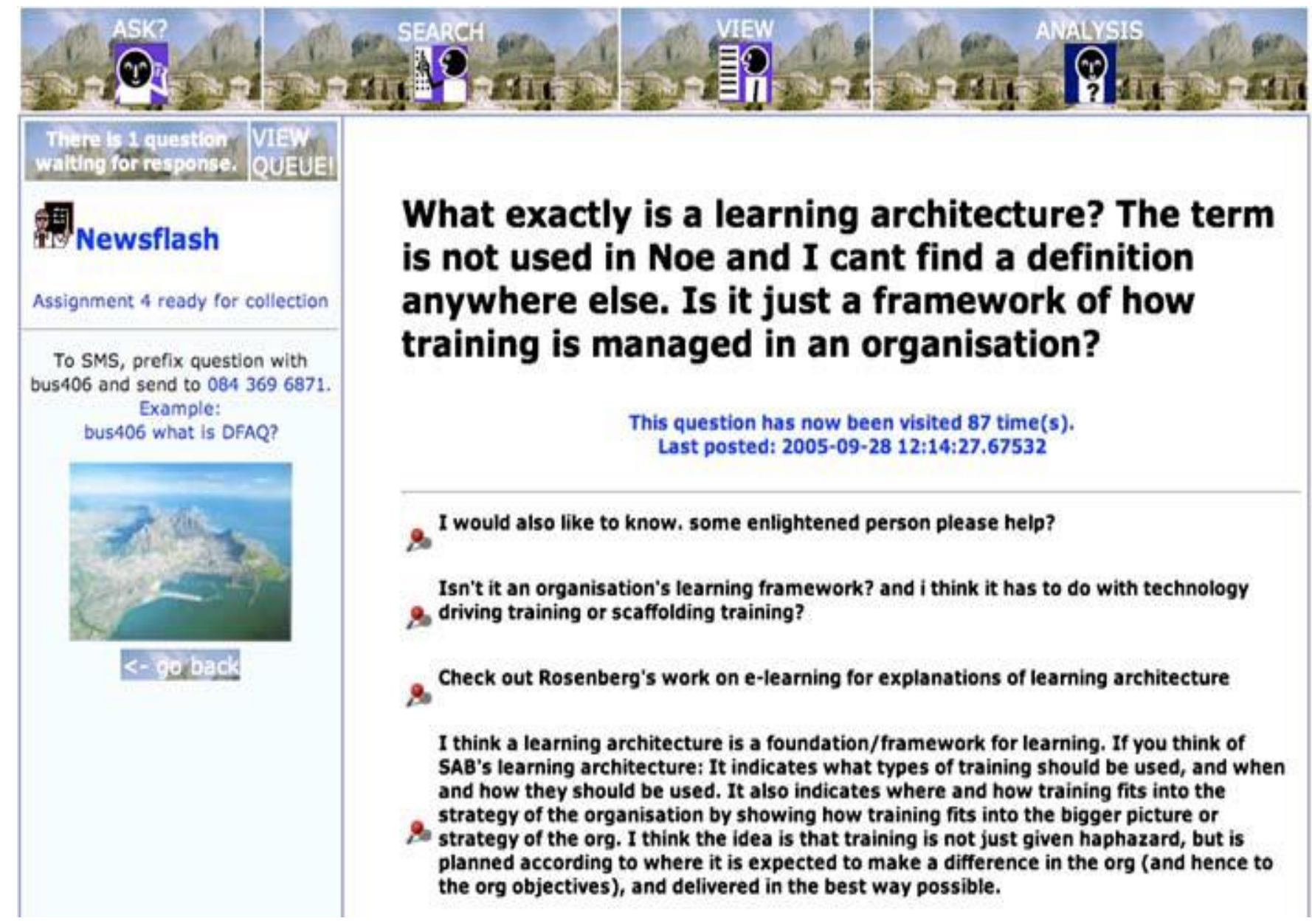

Fig. 1 Part of the DFAQ interface 


\subsection{Case study description}

The study was conducted with two cohorts of students in 2005 and 2006. In 2005 there were 28 students and 39 students in 2006. In both years students were registered for an honours course in Organisational Psychology at a South African university. These students came from diverse socio-historical backgrounds and with varying degrees of academic preparedness. The organizational learning module was a 9 week module and took place mid-way through the academic year. The objective of the module was to introduce students to the theory and practice of organizational learning. It was therefore assumed that students would use DFAQ to consult with one another on organizational learning related topics. Our assumption was that the multiple perceptions of students on questions posted in DFAQ would be course related and influenced by student's diverse backgrounds and multiple views. We therefore saw an opportunity for teaching the use and impact analysis of ICT (i.e. practice) in organizational learning through practical use of ICT in an authentic learning context. It was not the goal of the study to use students as surrogates of employees, but to give students a typical example of how employees learn from one another and how organization may build a knowledge resource from informal knowledge sharing among employees. The project focused on how learning principles support and promote change in organizations. There were three outcomes we hoped to achieve with the introduction of DFAQ: 1 . Support learners in understanding the topics as laid out in the course outline and guided by a textbook 2 . Use assignments to consolidate understanding through linking of theory to practice 3 . Build a knowledge resource from learner's interaction with peers while trying to achieve (1) and (2). While the successful accomplishment of tasks (assignments) was important, it was in the process of collaboration with peers, sharing alternative views, seeking and receiving information where actual learning lay. The use of DFAQ reinforced learning principles and the theory discussed in lectures and provided students with an applied example, an experiential opportunity and a reflection space for course related topics.

\subsection{Participants}

There were 67 course participants over the 2 years of which eight students volunteered for the focus group discussion. The focus group discussion took place in 2006 with participants who attended the course that year. The 2005 study was a pilot project which was refined in 2006 hence the formal data collection procedure took place in the year of the main study in 2006 . The eight participants were diverse in terms of their demographic characteristics (i.e. race, undergraduate degree, cultural background/nationality). Although participants were volunteers, the researchers attempted to minimize bias by opening participation to students who either actively or passively engaged with DFAQ. The eight participants were therefore representative of the entire class. Consent to participate in the focus group discussion was obtained.

\subsection{Data gathering and analysis}

Data was collected in two ways, (1) consultation artefacts recorded by the medium of interaction, DFAQ and (2) unstructured discussion with eight participants. 


\subsubsection{DFAQ artefacts}

During the 9 weeks, students attended face-to-face lectures and had access to the DFAQ tool. Although students had some level of trust for one another gained through face-to-face meetings, there were communication barriers when it came to consulting with peers who were not necessarily friends (Ng'ambi 2004). The integration of DFAQ in the organisational learning module was to compliment a face-to-face course with a tool specially designed to allow students to take responsibility for their own learning through facilitation of a $24 \mathrm{~h} / 7$ days anonymous consultation among students. The DFAQ artefacts were an outcome of online student consultations. In other words, DFAQ artefacts were a collection of students conceptions of knowledge expressed as questions and a subsequent flood of responses from peers. These responses constituted multiple conceptions constructed for the purpose of assisting peers to find answers to poised question. Questions were thus invitations to peers to share in finding answers to questions. Hardman (2005) reports that

...one of the most useful aspects of the DFAQ environment, for the lecturer at least, is the fact that students' and lecturer's questions/responses remain available for discussion outside of the lecture period, allowing one to return to questions and responses when one has had time to reflect on the lesson (p. 383).

We saw the persistence of DFAQ artefacts as one of the values; the other was that DFAQ provided a space for reflection as students had time to think about the responses before posting them.

\subsubsection{Focus group discussions}

The purpose of a focus group discussion was to elicit student experiences on how multiple perceptions of peers posted in response to questions asked in DFAQ may have enhanced understanding of organisational learning. In particular, the focus group was conducted to explore how students' experienced the tool and whether students' experiences reinforced or contradicted the researchers' objectives for using ICT in the course. The discussion was therefore unstructured and based on leading questions. Consent was obtained from participants to have the focus group discussion audio taped. The tape was transcribed and a thematic analysis based on Miles and Huberman's (1994) qualitative data analysis process was followed. In the next section, we analyse both the DFAQ artefacts and transcript from the focus group discussion. Congruent with thematic analysis, discussion of findings forms part of analysis.

\section{Analysis and discussion}

In 2005, 49 questions were posted in the DFAQ and 108 questions in 2006. Observations of interaction behaviour during the 2 years show that in 2005 references to questions ranged between 91 and eight, while in 2006 it was between 87 and seven. This suggests that although there were fewer questions posted in 2005, the questions were looked up more often as compared to 2006. The frequency of reference is indicative of either a shared interest in a question or an expression of 
interest in responding to a question. One of the features of DFAQ is the dynamic ranking of frequently referenced questions and the indication of when last questions were referenced. On the number of responses a question attracted, in 2005 the maximum number of responses to a question was eight and while in 2006 were 11. The relatively low responses in relation to frequency of reference suggest that students used DFAQ to read about peers' perspectives.

\subsection{Artefact analysis}

The question depicted in Fig. 1 is one of the many questions that focused on organisational learning. The question is significant in two ways. Firstly, embodied in the question is the student's understanding of the concept of learning architecture. He/she poses the question and exposes their understanding of the concept. Secondly, embodied in the question is the student's knowledge about the textbook and in particular the fact that it did not have a definition of learning architecture. Figure 1 shows a question posted in 2005 with four responses and visited 87 times. The popularity of the question (87 references) suggested that the question was of general interest to many students in class. This assertion is confirmed with a posting from a student which read "I would also like to know, some enlightened person please help?" Other responses from peers' uses phrases such as "...Isn't...I think" which suggest that although students were not sure, they were willing to take responsibility for their own learning. It can also be inferred from Fig. 1 that multiple perceptions may have shaped the understanding of both the author of the question and those that visited the question.

In the next question the query was not about understanding a concept in organisational learning but querying the importance of organizational learning. The question was significant in that here was an honours student wondering whether the theories learnt in the course were relevant in the work place (see Fig. 2):

There were nine responses with 67 references. Analyses of the responses suggest that both students' backgrounds and access to multiple perceptions may have influenced their opinions. It can be inferred that in response 27-41 the respondent agrees with the question-asker's sentiment but adds that it depended on how organisational learning was used, response 27-45 dismissed the question as irrelevant, while response 27-47 disagreed by arguing for the importance of organisational learning for competitive advantage, and response 27-50 (not visible in Fig. 2) draws from internship experience to argue that organisational learning theories did work in practice. Although it was difficult to say whether the multiple views convinced the author, the stream of responses opened up a forum of discussion around the topic and perhaps provided the student with varying perspectives to think about. Also posted in DFAQ were questions aimed at clarifying ambiguities in learning tasks. In these type of questions, students posted questions that elicited information from peers on what they understood was required of them in a particular assignment. The question below was one of the many in this category:

Someone, please can u clarify to me exactly what this assig entails? Im very confused?! Thanx;) 
i am still not convinced that organisational learning is everything it is cracked up to be, anybody keen to convinve me otherwise?

This question has now been visited 67 time(s). Last posted: 2006-08-28 10:18:51.633481.

Reference no: [27]

[27-41]: 8 organization. If used constructively and in the manner suited to those
participating in the training, it can definately be of benefit to both the organization
and the individual, as and increase in knowledge is always of benefit.

[27-42]: 8 Are you refering to the lectures? or in the real corporate world?

[27-44]: $\&$ Real world, happy with the course not sure about the relevance

[27-45]: $\&$ I can't see how you can question the relevance, I think we have enough evidence to support the importance

Organisational learning can help an organisation ensure a competitive edge. This may help employees improve their skills and competencies and continually operate and perform better than their competition. that is organisational learning should be strategically aligned to help the org achieve its mission/vissions etc.

[27-47]: However it is up the individual to react/utilise this facility. Learning could also motivate employees as they are not doing the same boring job over and over again but exposed to more knowledge and able to be promoted or move into other fields. Learning is expensive and to have you r organisation willing pay for it is an awesome benefit that some employees do not recognise. Maybe you are not yet working and can not practically see the awesome benefits or org learning.

Fig. 2 Questioning the gap between theory and practice

The interest the question generated (measured in terms of 83 references) suggested that other students may have been in similar predicament. The six responses posted from peers are as follows:

I think it has to do with outlining a learning process of UPS, so how UPS is going to strategise and set up learning systems in the organisation, does that help, what do other people think?

A peer in responding to the question began by saying "...I think..." suggesting that it was an attempt. Also noteworthy was the signing off of the message "...does that help..." and extending an invite to others for comments. It can be inferred that the student was willing to be influenced by other perspectives. This suggested that although the student had not identified with the initial question the activity on DFAQ stimulated the formation of another related question.

I agree. $X Y$ also mentioned that you could draw the new learning framework, like SAB did and then also demonstrate how this new learning framework affects the bottom line, i.e how it affects UPS's business strategy.

The aim of this response seemed to endorse the earlier response whereby reaffirming the other student's interpretation of the requirements of the assignment. 
I thought it had to do with building learning into the organisation and integrating learning into the business to create a learning organisation?

This response took a divergent view by diplomatically disagreeing "...I thought..." This was significant in that the student brought a different perceptive to the understanding of a task.

I think the assignment is extremely straightforward, whats not to understand! you are confusing yourself!

Here the student neither rejected nor confirmed what others had said except to say, as far as he/she was concerned there was nothing confusing about the assignment:

The last comment...how is it easy? please elaborate

In the above artefact analyses the gap between what students knew and what they could potentially know was embodied in the questions they asked and the responses they received. The interest in peer's questions as evidenced by the number of references suggests that students regarded questions from peers as invitations to assist fellow students in finding solutions to their questions. As a consequence, DFAQ provided a space for students to ask course related questions, affective questions and general clarification questions. These expressions provided the lecturer with an understanding of how students were engaging with course content, where they were struggling and what information they still needed to know. In the example above the multiple postings of responses potentially helped shape the understanding of other students.

\subsection{Thematic analysis}

Five themes were identified from the focus group discussions: (1) how and why students used the DFAQ environment, (2) why students found the DFAQ helpful, (3) affective responses to the DFAQ, (4) critical feedback about DFAQ and (5) the theory practice link.

\section{Theme 1 How and why students used the DFAQ?}

The theme represents participants' responses to how and why they used DFAQ. The responses differed depending on whether the user was active or passive when in the DFAQ environment. These differences are reflected below. Active users posted and answered questions while passive users tended to read postings and gather information without posting questions of their own or answering posted questions. Some users suggest being active in posting questions but passive when it came to responding to questions.

...I felt I would end up giving the wrong answers so I felt inhibited in that way. I did not want to post an answer there when I was not feeling confident.

Although the DFAQ environment was anonymous, the statement suggests that some students were still not confident enough to attempt answering questions for which they were unsure of the correct answer. Artefacts exposed the learner's potential levels of development and opened avenues through which timely interventions could be designed for the benefit of current cohort of learners. Other 
observations included reports to the effect that DFAQ guided them (students) in the parameters of the assignment question, provided a space for clarified understanding of the objectives of the exercise and confirmed or disconfirmed to users on what the "right track" was. In this case, the tool provided individualised guidance to a learner hence facilitating the attainment of a level of potential development. This view is consistent with the Vygotsky's notion of addressing the zone of proximal development in collaboration with more capable peers. Students reported that DFAQ stimulated learning and cultivated inquiring minds.

I would go like "Wow" and it would make me go and read more and focus more on the assignments...

Other students reported using DFAQ for self-validation through establishing whether or not they were on the right track.

I would get all this information and then I would go to DFAQ—and say "OK I am on the right track or No I am going down the garden path.

They commented that checking that they were on the right track made them feel reassured, affirmed and increased confidence in their work. We infer from this finding that access to a knowledge resource subsumed the role of an adult or capable peer, whereby affirming learners and building their confidence. The impact of multiple perspectives from a wide spectrum of people was also observed. Some students learnt from readings postings from other students who mentioned things she/he (the reader) had not thought of. Other participants revealed that the anonymity of the DFAQ allowed them to ask questions that would not normally have had the confidence or courage to ask.

I think for me I do not have a lot of confidence in my own thought processes like I don't believe that the things that I think are right or particularly innovative or smart so I am very withdrawn when it comes to expressing what I think and like DFAQ was helpful... because I did not have to go and expose myself...

Participants commented that they had to express themselves clearly when using the tool, more clearly than in face-to-face communication. The need for clear, focused questions inhibited some participants from actively using the tool.

I think sometimes you feel like you can't express it properly when it is almost too complicated to ask in a paragraph...

Some students explained that DFAQ encouraged them to share information with their classmates as opposed to sharing exclusively with their friends. DFAQ offered students an opportunity and choice to work with other people in a more collaborative environment.

I think DFAQ is heading towards a sort of collective way of learning and that we could actually learn together and all of us improve our skills and abilities, so I think if we changed our mindset of what learning is about then it is not about only personal achievement and learning but if we could collectively learn then I 
think the DFAQ would become more affective because people would then share information and not actually hold onto it.

The statement suggests that DFAQ may have had a transformative effect by way of impacting on user choices of whether to share or to hold onto information. The student added that her/his experience of learning was individualistic.

...undergrad was very much an individual learning time for me and I did not, when I came into honours I thought it would be exactly the same. I thought I had to go and study, get my own information and present whatever I processed, whereas I think that learning collaboratively is a lot more effective and toward the end I started using it and it was a lot more helpful for me to learn that way, so if you could use it in undergrad courses, I think it would help people's learning so much more.

\section{Theme 2 Why students found the DFAQ helpful?}

The following theme highlights how DFAQ was perceived to be of benefit to learners. A participant explained that she found DFAQ useful as a learning tool because it was innovative. She explained that the "newness" of the tool stimulated her to engage with DFAQ.

It was a good learning tool, I think and also it was just different as well and think that sort of helps like you sort of get struck in the rut of learning sometimes and just to have a different avenue to go to and a different way to get information...it was just different and it just was more useful.

Participants also found the tool helped break down the boundary between the lecturer and the student making the learning experience less formal and the lecturer more accessible. The participants reported that the anonymity further facilitated this. Our interpretation of this finding is that learners may have required a "safe and unintimidating" environment in which to confront their own misunderstanding or misconceptions and ways of moving to the next level of development using DFAQ. Anonymous knowledge sharing seemed to provide the space.

\section{Theme 3 Affective responses to the DFAQ}

This theme summarises the affective responses of the participants to the tool. Most participants had a positive reaction towards the tool; the positive reactions are captured in comments like:

- I loved it.

- DFAQ is great.

- DFAQ is a very nice resource.

- I have often thought why can't we have it for this course or that course or why can't this be such a nice resource for this person to use for that thing... and it is a nice thing to lean on and to have there as a resource, so I have often found that it was missing in other areas.

- I think it was great. We are always in close contact with each other and always in contact with lecturers and stuff so it aided our learning and communication and I think in other courses it would be even more beneficial. 
Student attitude towards a mediating tool is important. These comments show that learners were positive about the tool and explain why participants reported that they increasingly used the tool as the course progressed and as they became more comfortable with the technology. They commented that the tool should be available to them on all courses throughout the year and that availability would further increase their activity in the environment.

\section{Theme 4 Critical feedback about the tool}

Some participants felt that email or telephone was a more effective way of communicating with the lecturer. Asked whether any of the learners had emailed the lecturer during the course, none but one had sent one email. And none of the learners had phoned the lecturer. Other participants commented that they required more than just a written response to a question and wanted to have a conversation about a certain subject. One participant found that she expressed her questions better verbally and having to type text inhibited her use of the DFAQ.

...I am busy grabbing all kinds of ideas, thinking about them, still thinking how I can interlink them and how they make a picture and how they apply, you see I am still in the process of doing this, so in other words to ask a question about all these different thoughts that I have, to ask one question, it is difficult because I am still in the process of forming my opinion, forming my ideas, so I did not find like I could ask what I wanted to ask sometimes...

The statement suggests that the student de-constructed and re-constructed knowledge. This inference is based on the continuous interrogation of reading materials and asking questions about what was read. This suggests that DFAQ may not have been suitable for all students depending on their learning styles. Other participants felt inhibited to participate in the environment because they were not sure if they understood the subject matter well enough and were afraid of giving other students incorrect information. This constraint around the level of engagement might be shaped by context and personal histories of learners. To this end, fear of giving incorrect information could be an outcome of previous experiences. This was an unexpected finding as we thought anonymity in DFAQ would have encouraged students to attempt to respond to questions regardless of their level of confidence. The learner exploited the anonymous nature of DFAQ and attempted to "form opinions" in response to questions. Other postings took different forms depending on whether students were expressing an opinion or were offering an actual answer to a question. The views that DFAQ increased many students' confidence were reported. One participant suggested the lecturer invites comments on a certain pertinent theme or starts a debate to stimulate activity in the environment. Some participants felt that the environment should also accommodate non-academic conversations. Some perceptions of abuse of DFAQ were observed (see Fig. 3)

\section{Theme 5 Theory practice link}

Some participants felt that using the DFAQ gave them an opportunity to relate to the theory of organisational learning in a practical and applied setting. 


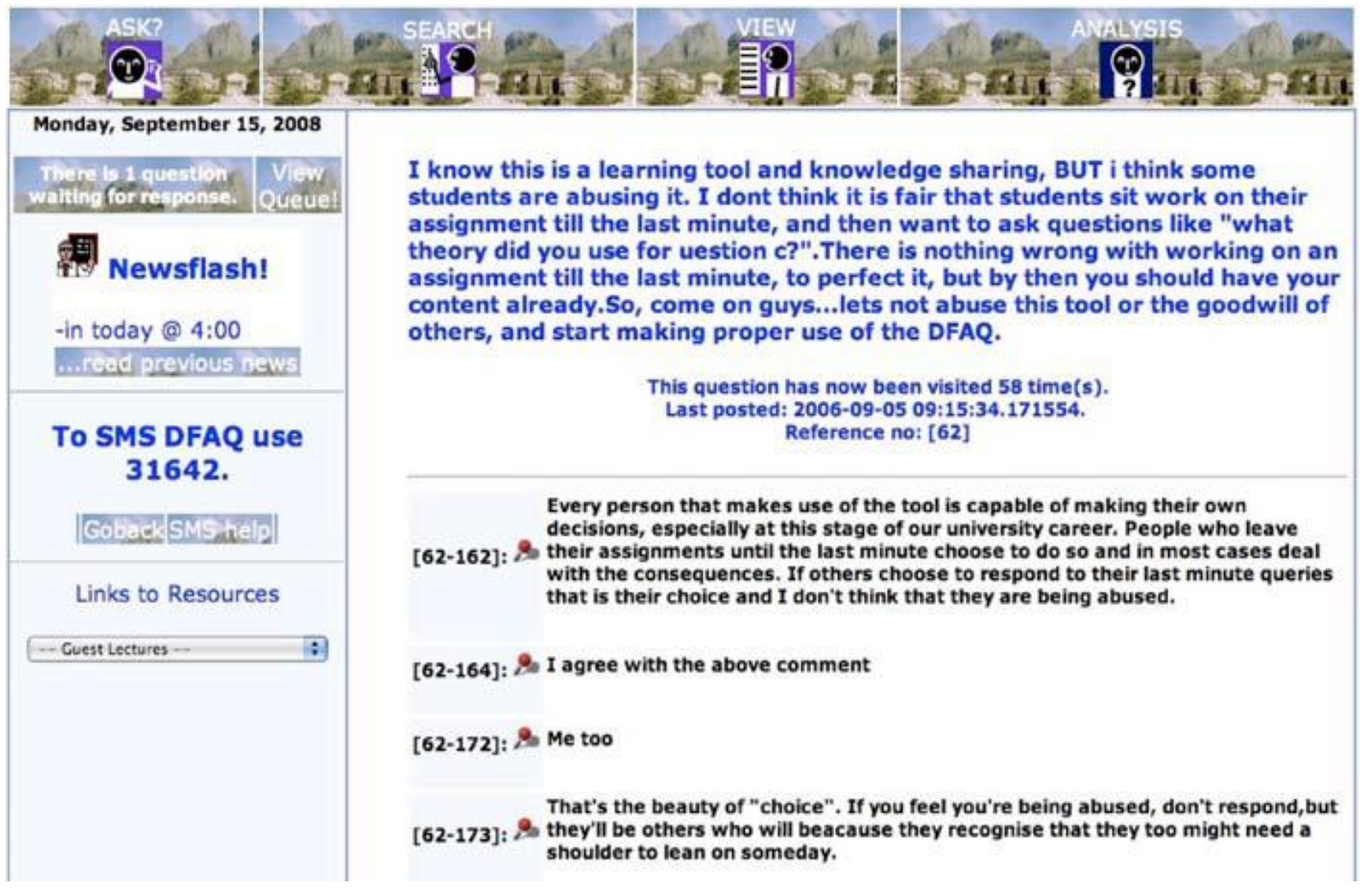

Fig. 3 Perceptions of abusive use of DFAQ

I think it is nice to have contact with a tool like DFAQ because just for instance we go into training we could maybe think about this as a tool to use in the work-place, it is nice to have exposure to a tool, a real-life learning tool.

One participant proposed that DFAQ could be further integrated into the course by having an assignment set on it. This could aid in getting students to use the tool while having first-hand experience of a learning technology in an organisational setting.

\section{Concluding discussion}

The assumption underlying this project, and the subsequent research, was that facilitating the articulation of learners' multiple perspectives of understanding in a shared forum had the potential to provide individualised student support and critical educational information to the educator. This information would include how students on the module were coping with the subject matter and identify gaps in their learning. The motivation for using the tool was to increase the responsiveness of the teacher to the students by exposing the learning gap during and throughout the module. Engagement with the tool opened channels for communication between the lecturer and the students and the students themselves. Instead of conducting summative evaluations at the end of the module the lecturer was generating formative evaluative information as the modules progressed. The introduction of DFAQ into the Organisational Learning module afforded the lecturer the opportunity to constantly monitor the gap between the learners' current levels of knowledge and the desired course outcomes. At the onset of the modules, in the first lecture, students were asked what they wanted to learn about organisational learning. The 
learners were, for the most part, unable to answer the question; they had not given much thought to what they wanted to learn in the module. Once the learners began engaging with the course materials they began to develop a better feel for the subject and started asking questions via the DFAQ. These questions were used as indicators of level of knowledge (and interest). The questions were addressed in the environment and opened up points for discussion in the formal lectures. The lecturer was able to refine, adapt and repurpose teaching materials in response to the learners' emerging learning requirements whereby creating a dynamic and interactive learning experience for both the learners and the lecturer. Being able to constantly gauge learners' current level of knowledge through the kinds of questions asked in the DFAQ had positive spin-offs. Communicating with the learners through the environment helped the lecturer create a responsive, sensitive and appropriate learning environment in the formal classroom. As mentioned in the analysis of the focus group discussion, the anonymity encouraged learner participation and gave learners an opportunity to engage with difficult aspects of the course or the assignments in a non-threatening anonymous environment. The learning experience was enhanced through multiple perspectives elicited through learners' desire to help each other to find solutions to shared problems. If one accepts that the formal lecture is limited in its capacity to impart knowledge and that real learning happens outside of the classroom, one should be able to appreciate the value of the DFAQ as evidenced in the results of this study. The study shows that DFAQ appears to stimulate learners' enthusiasm for the subject matter and creates opportunities for self-managed and collaborative learning. In summary this paper discussed a project aimed at investigating the value of providing an anonymous safe environment where learners could freely ask questions and express themselves without inhibitions and assessed the impact of this environment on the learning experience. A secondary goal of the project was to allow the knowledge resource to serve as useful feedback to the educator on the knowledge levels of learners. The realisation of these goals required that an environment be created that fosters knowledge creation and sharing. The DFAQ embodies this environment and reflecting on the results of the focus group discussion it stands to reason that this environment succeeded in stimulating knowledge sharing and peer learning.

\section{References}

Belanger, F., \& Jordan, H. D. (2000). Evaluation and implementation of distance learning: Technologies, tools and techniques. London: Idea Group.

Hardman, J. (2005). Activity theory as a potential framework for technology research in an unequal terrain. South African Journal of Higher Education, 19(2), 378-391.

Jansen, K. (2004). Unpacking and re-packing knowledge in development. In D. Kolb, W. Panters, \& H. Siebers (Eds.), Globalisation and development (pp. 163-190). Netherlands: Kluwer Academic.

Marquardt, M. (2005). Leading with questions. San Francisco: Jossey-Bass.

Miles, M. B., \& Huberman, A. M. (1994). Qualitative data analysis (2nd ed.). California: Sage.

Ng'ambi, D. (2004). Towards a knowledge sharing framework based on student questions: the case for a dynamic FAQ environment. Ph.D. thesis (unpublished). University of Cape Town.

Salmon, G. (2000). E-Moderating: The key to teaching and learning online. London: Kogan Page.

Vygotsky, L. S. (1978). In M. Cole, V. John-Steiner, S. Scribner, \& E. Souberman (Eds.),Mind in society: The development of higher psychological processes. Cambridge, MA: Harvard University Press. 